\title{
Integrasi Relawan Teknologi Informasi dan Komunikasi dalam Sistem Pendidikan Tinggi
}

\author{
Rinda Cahyana $^{1}$
}

\begin{abstract}
Abstrak
Pembangunan masyarakat informasi dalam area geografis tertentu diwujudkan dengan melibatkan sumber daya manusia yang mampu mengubah kondisi masyarakat secara berkelanjutan dari buta menjadi melek dan cerdas digital. Mobilisasi sumber daya manusia dapat dilakukan di perguruan tinggi. Perubahan kondisi masyarakat dapat diusahakan melalui aktivitas pengajaran, penelitian, dan pengabdian kepada masyarakat. Artikel ini mendiskusikan pendekatan integrasi relawan TIK dalam sistem pendidikan tinggi dalam bentuk kegiatan intra dan ekstra kurikuler. Keterbatasan program, fasilitas, perangkat, sumber daya manusia, dan dana membuka kesempatan bagi organisasi relawan TIK eksternal kampus untuk bermitra dengan perguruan tinggi dalam melaksanakan program Relawan TIK Abdi Masyarakat. Pintu kerjasama terbuka dan berkelanjutan selama organisasi tersebut mampu untuk terus menyediakan keluaran program kerjasama sesuai standar nasional pendidikan tinggi dan tidak bisa diupayakan sendiri oleh perguruan tinggi.
\end{abstract}

Kata Kunci: Relawan, Teknologi, Pengabdian, Pendidikan Tinggi

\section{Pendahuluan}

Relawan adalah orang atau kelompok yang berkomitmen menyediakan waktu dan kemampuannya untuk membantu kepentingan umum demi amal. Orang yang terlibat dalam kegiatan relawan sangat variatif, mulai dari kelompok amatir hingga profesional, tua ataupun muda (Cahyana, 2016; Acevedo, 2005). Di antara tempat yang menjadi lokasi perekrutan relawan sekaligus mitra penerima manfaat relawan adalah lembaga pendidikan (Cahyana, 2014; Attwood, et al., 2003; Musick \& Wilson, 2007; Linda, 2000). Dosen dan mahasiswa program sarjana dapat menjadi relawan dalam rangka melaksanakan kewajiban pengabdian kepada masyarakat.

Di Indonesia terdapat banyak organisasi relawan yang bergerak di berbagai bidang, di antaranya adalah Relawan TIK (Teknologi Informasi dan Komunikasi) Indonesia. Perkumpulan ini dibentuk oleh relawan dan komunitas dalam bidang TIK se Indonesia sebagai medium komunikasi, koordinasi, dan kolaborasi untuk mengembangkan pengetahuan, keterampilan, dan sikap yang dapat memajukan kesejahteraan dan mencerdaskan kehidupan bangsa dengan TIK, sejalan dengan kewajiban pengabdian kepada masyarakat yang diemban oleh sivitas akademika (Kemenristekdikti, 2015; Kemkominfo, 2011). Selain itu organisasi kemasyarakatan ini dibentuk untuk merencanakan, melaksanakan, dan mengawasi pembangunan masyarakat informasi Indonesia bersama unsur quadruple helix yang meliputi pemerintah, perusahaan, perguruan tinggi, dan unsur masyarakat lainnya (Kemkominfo, 2011).

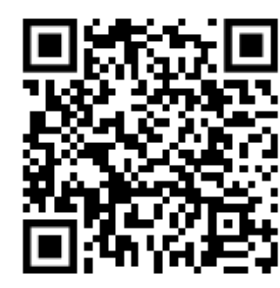

1. Program Studi Informatika, Sekolah Tinggi Teknologi Garut, Jl. Mayor Syamsu No. 1 Garut 44151, Indonesia

${ }^{*}$ Email of Corresponding Author : rindacahyana@sttgarut.ac.id

Submitted : Agustus 2018

Accepted November 2018

JAS-PT

JURNAL ANALISIS SISTEM PENDIDIKAN TINGGI

ISSN $2580-5339$

eISSN 2620 - 5718

Volume 2

Nomor 2

DESEMBER 2018

Hal $61-70$

FORUM DOSEN INDONESIA 
Masyarakat informasi adalah budaya baru yang terwujud oleh kebebasan dalam mengakses, membuat, mendistribusikan, dan menggunakan informasi untuk keuntungan kompetitif dengan TIK (Karvalics, 2007; Gudauskas, 2011). Membangun masyarakat informasi dalam lingkup area geografis tertentu membutuhkan TIK, sumber daya manusia, dan layanan yang tidak sedikit. Diperlukan upaya berkelanjutan untuk mengubah kondisi masyarakat dari buta digital menjadi melek digital, di mana masyarakat menyadari arti penting penguasaan informasi dan TIK serta mampu menggunakan TIK untuk mengakses, membuat, mendistribusikan, dan menggunakan informasi (Cahyana, 2014). Tidak berhenti di sana, masyarakat yang telah melek digital harus menjadi cerdas digital di mana kemampuannya tersebut memberikan keuntungan dan tidak merugikan.

Untuk mengubah kondisi masyarakat tersebut, relawan TIK harus melaksanakan layanan berikut ini secara berkelanjutan di tengah masyarakat (Alisandi \& Cahyana, 2015; Cahyana, 2014; Cahyana, 2015; Cahyana, 2016):

1. Layanan Informasi, meliputi aktivitas pencarian dan pembuatan informasi dalam beragam format serta penyampaiannya kepada pengguna informasi di dunia nyata dan dunia maya;

2. Layanan perangkat, meliputi aktivitas pembelian atau pembuatan perangkat TIK, pemasangan dan pemeliharaannya (perbaikan dan peningkatan fungsi); dan

3. Layanan perangkat, meliputi aktivitas pendidikan, pelatihan, dan bantuan teknis di dunia nyata dan dunia maya.

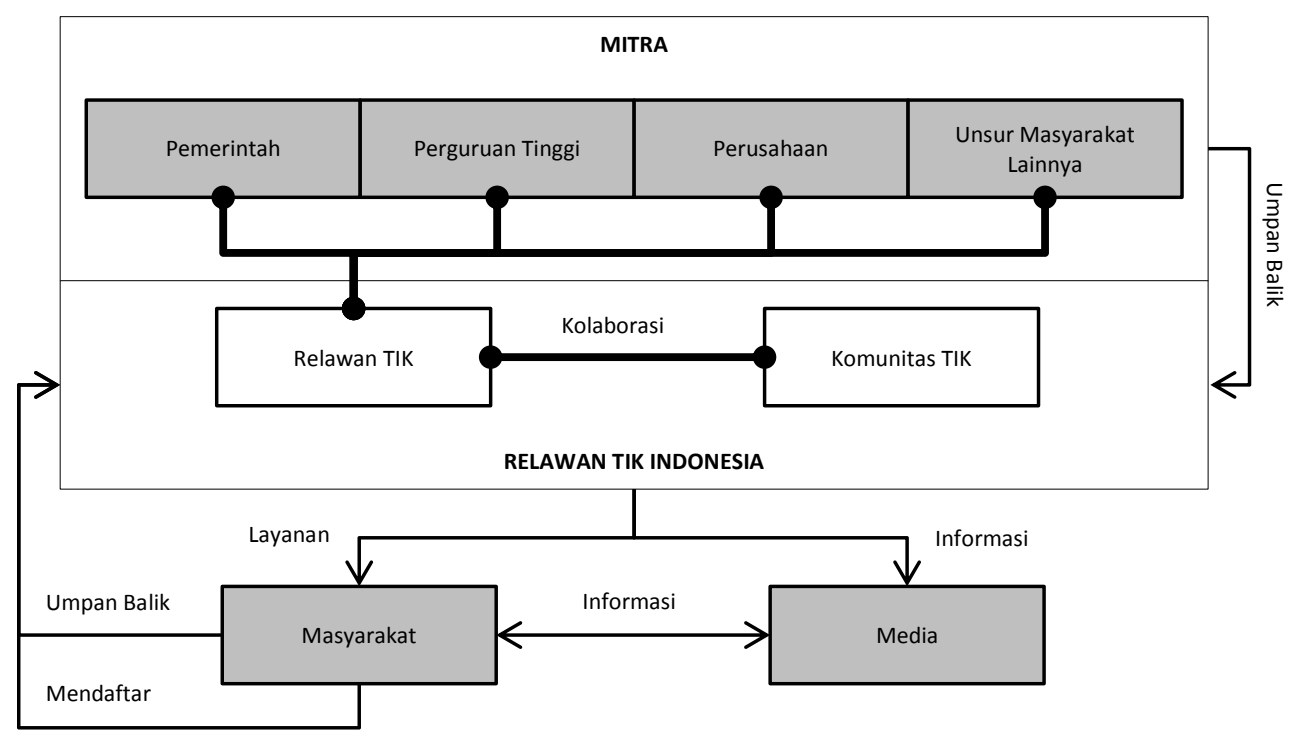

\section{Gambar 1. Relawan TIK Indonesia}

Masyarakat dapat direkrut sebagai relawan untuk melaksanakan layanan tersebut. Perekrutan relawan ini harus periodik mengingat relawan ini bukan merupakan pekerjaan tetap. Masyarakat dapat membuat komitmen menjadi relawan dalam rentang

JAS-PT

JURNAL ANALISIS SISTEM PENDIDIKAN TINGG ISSN $2580-5339$ eISSN $2620-5718$

Volume 2

Nomor 2

DESEMBER 2018

Hal 61- 70 waktu tertentu atau hanya untuk satu kali tugas pelayanan. Upaya mengubah kondisi mayarakat dalam area geografis yang luas itu tidak sebentar sehingga pengelola Relawan TIK sangat membutuhkan ketersediaan sumber daya manusia.

Perguruan tinggi menerima mahasiswa baru setiap tahunnya sehingga memiliki sumber daya manusia dan program pengabdian kepada masyarakat yang berkelanjutan. Sivitas akademika dari berbagai bidang ilmu dapat dimobilisasi menjadi relawan TIK 
mengingat adanya kebutuhan masyarakat umum di segala bidang akan pemanfaatan informasi dengan TIK. Perguruan tinggi dapat turut serta melaksanakan pembangunan masyarakat informasi di wilayahnya dalam bentuk kegiatan pengabdian kepada masyarakat bersama mitranya yang ditetapkannya sendiri. Hal tersebut menempatkan peguruan tinggi dalam daftar mitra strategis bagi organisasi Relawan TIK. Namun tidak mudah bagi organisasi Relawan TIK untuk menjadi mitra perguruan tinggi.

Artikel ini menjelaskan pendekatan integrasi relawan TIK dalam sistem pendidikan tinggi. Pendekatan tersebut harus memberikan sejumlah keluaran sesuai SNPT (Standar Nasional Pendidikan Tinggi) yang bermanfaat bagi perguruan tinggi agar terbuka pintu kemitraan bagi organisasi Relawan TIK. Dijelaskan bagaimana relawan TIK dilaksanakan di perguruan tinggi sebagai kegiatan intra kurikuler dan ekstra kurikuler.

\section{Pendekatan Integrasi}

Cahyana \& Sagala (2017) telah menyajikan model sistem perguruan tinggi yang meliputi: 1) aktivitas masukan yang mendata permasalahan dunia nyata yang berasal dari mitra atau penerapan ilmu pengetahuan dan teknologi; 2) proses penyelesaian masalah dalam aktivitas pengajaran, penelitian, dan pengabdian kepada masyarakat; serta 3) aktivitas keluaran yang memberikan pengetahuan dan / atau teknologi yang dapat mengubah kondisi masyarakat. Integrasi relawan TIK dalam sistem pendidikan tinggi dapat dicapai dengan menjadikan aktivitas relawan TIK sebagai bagian dari aktivitas masukan, pemrosesan, dan keluaran dari sistem pendidikan tinggi. Prinsip aktivitas relawan adalah sukarela, tetapi dalam sistem pendidikan setiap peserta didik dapat mengikuti pembelajaran dalam kondisi suka ataupun tidak suka. Misalnya mahasiswa dapat membantu masyarakat dalam kegiatan KKN (Kuliah Kerja Nyata) secara sukarela ataupun terpaksa. Walau demikian KKN pada akhirnya harus menjadikan mahasiswa dapat mewarisi sifat baik yang diajarkan di dalam perkuliahan Agama seperti sedekah kemampuan sesuai bidang ilmu secara ikhlas atau sukarela. Dijelaskan dalam SNPT bahwa KKN sebagai bentuk pembelajaran pengabdian kepada masyarakat merupakan sarana penerapan sikap serta penggalian pengetahuan dan keterampilan dalam kehidupan keagamaan dan sosial kemasyarakatan (Kemenristekdikti, 2015).

Aktivitas relawan TIK dapat diintegrasikan dalam pembelajaran, seperti dalam mata kuliah KKN. Sebagai bentuk pembelajaran pengabdian kepada masyarakat, KKN dapat dilaksanakan berupa pelayanan kepada masyarakat. Layanan yang diberikannya dapat berupa layanan relawan TIK yang meliputi layanan informasi, layanan perangkat, dan layanan pengguna. Dalam pelayanan tersebut mahasiswa menerapkan ilmu pengetahuan dengan TIK dalam bidang ilmunya dengan mengikuti tahapan peningkatan kapasitas masyarakat yang meliputi penyadaran / pendidikan, pelatihan, dan bantuan teknis paska pelatihan. Manfaat yang diharapkan dari KKN adalah pemanfaatan TIK yang dapat meningkatkan tarap hidup dan kesejahteraan masyarakat.

KKN meliputi dua kewajiban perguruan tinggi, yakni pengajaran dan pengabdian kepada masyarakat. KKN dapat diselenggarakan dalam mono atau muti disiplin (bidang ilmu) sesuai rencana strategis perguruan tinggi. Kegiatannya KKN dalam bentuk relawan TIK dapat dikelompokan ke dalam tiga tahapan sebagaimana tampak pada gambar 3. Selanjutnya ditentukan aktivitas untuk setiap tahapannya. Sebagian aktivitasnya yang ditandai dengan warna abu-abu diadopsi dari kewajiban unit kerja

\footnotetext{
JAS-PT

JURNAL ANALISIS SISTEM PENDIDIKAN TINGGI ISSN $2580-5339$ eISSN $2620-5718$ Volume 2 Nomor 2 Desember 2018 Hal $61-70$

FORUM DOSEN INDONESIA
} 
pengelola program pengabdian kepada masyarakat yang tertuang dalam SNPT (Kemenristekdikti, 2015). Aktivitasnya diawali dengan penetapan tujuan, sasaran, dan aktivitas sesuai rencana strategis perguruan tinggi. Aktivitas tersebut dalam model sistem perubahan pendidikan tinggi disebut aktivitas kendali (Cahyana \& Sagala, 2017).

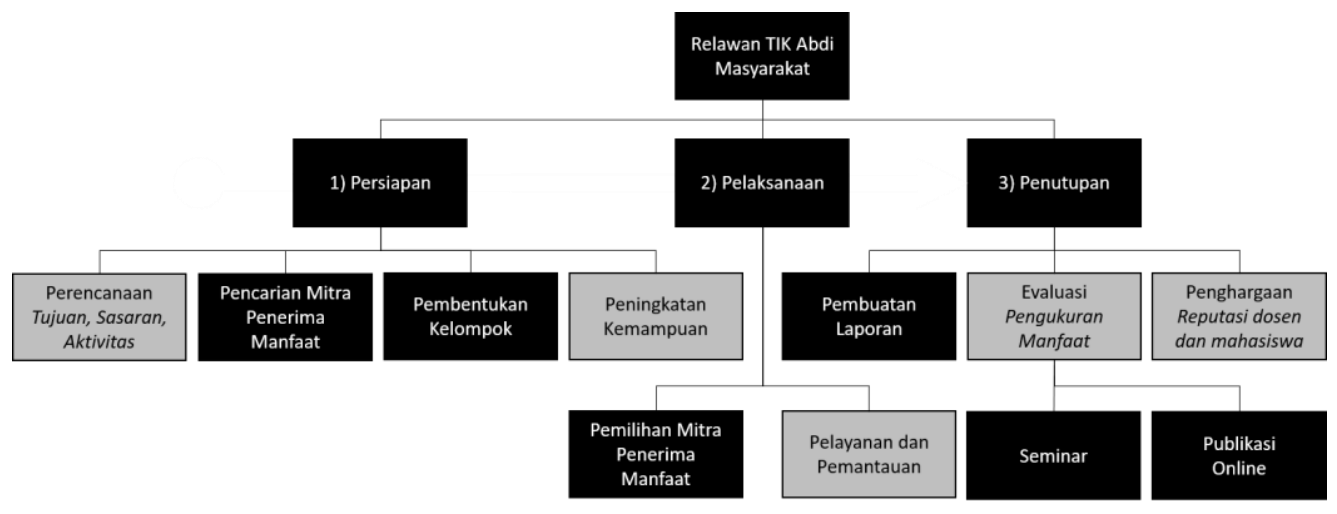

Gambar 2. Work Breakdown Structure KKN

Mahasiswa sebagai relawan TIK melaksanakan tugas pelayanan secara berkelompok. Kemampuannya dalam melaksanakan tugas pelayanan dibangun dalam aktivitas peningkatan kemampuan. Selanjutnya seluruh kelompok menyampaikan layanannya kepada mitra penerima manfaat di bawah pantauan / bimbingan dosen. Tahap pelaksanaannya sekitar satu hingga dua bulan pada saat libur panjang. Bila mata kuliah KKN diletakan pada semester genap sebelum tahap pelaksanaan, maka aktivitas peningkatan kemampuan dapat dilaksanakan di dalam mata kuliah KKN. Namun bila tahap penutupan membutuhkan waktu pelaksanaan yang lama, mata kuliah KKN dapat diletakan pada semester ganjil dan diisi oleh aktivitas dalam tahap penutupan. Seluruh aktivitas dalam tahap persiapan dan pelaksanaan dapat dilaksanakan pada saat libur panjang. Tahap persiapan juga dapat dilaksanakan pada matakuliah khusus pada semester genap sebelum pelaksanaan. Misalnya mata kuliah Relawan TIK yang menyajikan pemahaman teoritis dan praktis seputar relawan TIK, serta membangun keterampilan pelayanan dan sikap relawan TIK.

Evaluasi dilakukan oleh tim penilai / penguji (dosen) berdasarkan laporan akhir yang dibuat oleh seluruh kelompok relawan TIK. Apabila memperhatikan SNPT (Kemenristekdikti, 2015), evaluasinya dapat dilakukan dengan melalui pengukuran manfaat berupa:

1. Perubahan sikap, pengetahuan, dan keterampilan mitra penerima mafaat sesuai dengan tujuan program;

2. Potensi pemanfaatan ilmu pengetahuan dan TIK oleh masyarakat secara berkelanjutan; dan

3. Terjadinya pematangan mahasiswa.

Klarifikasi laporan akhir kepada kelompok relawan TIK dapat dilakukan oleh para penilai atau audien dalam seminar. Agar hasil KKN dapat diketahui dan / atau

JAS-PT

JURNAL ANALISIS SISTEM PENDIDIKAN TINGGI

ISSN $2580-5339$

eISSN $2620-5718$

Volume 2

Nomor 2

DESEMBER 2018

Hal $61-70$

FORUM DOSEN INDONESIA dimanfaatkan lebih luas lagi, sebaiknya diterbitkan dalam jurnal online pengabdian kepada masyarakat. Berdasarkan penilaian tersebut relawan TIK terbaik, baik perseorangan atau kelompok diberikan penghargaan oleh unit pengelola pengabdian kepada masyarakat atau instansi tertentu selaku mitra pendukung KKN.

Bila program Relawan TIK Abdi Masyarakat tidak bisa dilaksanakan dalam bentuk intra kurikuler, maka pelaksanaannya dapat dilaksanakan dalam bentuk ekstra kurikuler 
berupa kegiatan kemahasiswaan atau pengabdian kepada masyarakat yang dilaksanakan oleh unit pengelola atau tim dosen. Program tersebut dapat dijadikan sebagai program kerja tahunan bila rutin dilaksanakan. Selain itu pengabdian kepada masyarakat dapat dilaksanakan selama satu semester atau lebih dalam bentuk program pelayanan mingguan. Hasil pelayanannya dapat dijadikan material penelitian dan disajikan oleh dosen atau mahasiswa di akhir semester dalam pertemuan ilmiah di dunia nyata atau secara daring yang dihadiri oleh peserta dari luar kampus.

Bila organisasi Relawan TIK berdiri di dalam kampus, maka daur hidup kegiatannya sebagaimana tampak pada gambar 3. Anggota Relawan TIK dibagi menjadi dua kelompok, yakni fungsional yang melaksanakan pelayanan di tengah masyarakat, dan struktural yang mengelola organsiasi dan menjalankan program kerja organisasi.

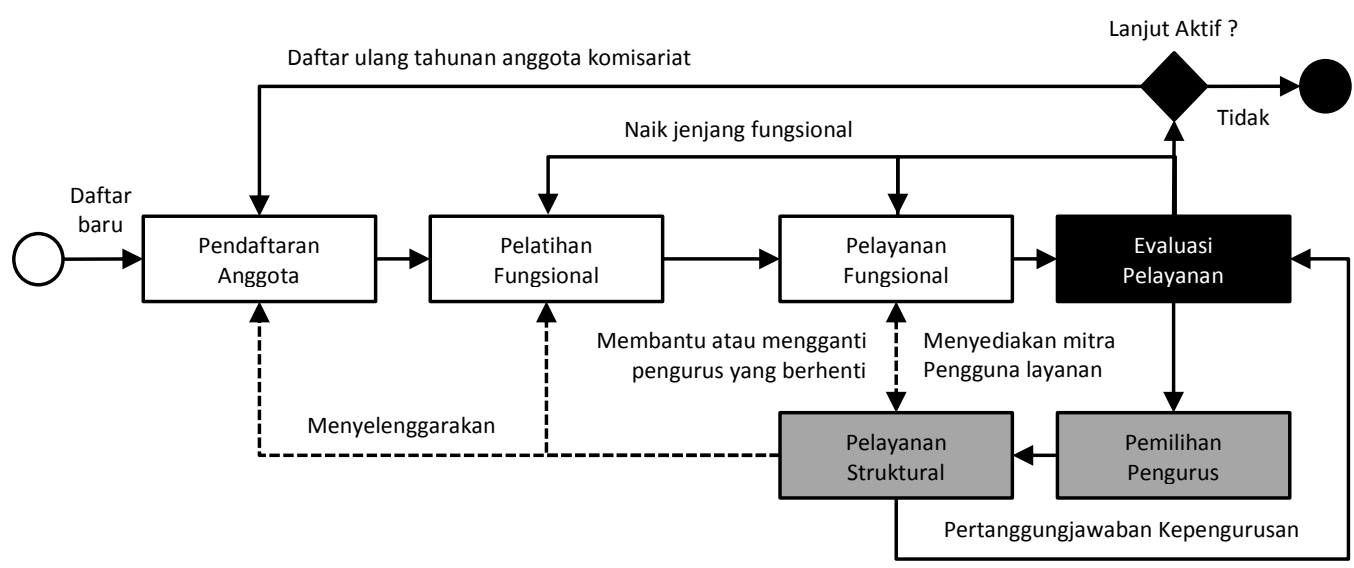

Gambar 3. Daur Hidup Pelayanan Relawan TIK

Agar anggota tidak merasa jenuh, kegiatannya dibuat bervariasi. Dengan ketentuan tertentu anggota dapat beralih dari satu jenjang fungsional ke jenjang lainnya. Jenjang tersebut disusun mengikuti tingkatan dapat meliputi pelatih calon anggota dan pengurus, pengelola organisasi / pengurus, dan perintis organisasi di luar kampus (Cahyana, 2014; Cahyana, 2015). Fungsi pengelola diwujudkan dalam pelayanan internal untuk membantu kepengurusan atau pejabat struktural tertentu dalam melaksanakan tugas pokok dan fungsinya dalam organisasi Relawan TIK. Memastikan keberadaan anggota ini penting mengingat pembangunan masyarakat informasi dilakukan dalam kurun waktu tidak sebentar.

\section{Membangun Kemitraan}

Masalah kondisi masyarakat yang harus diubah dari buta menjadi melek dan cerdas digital dapat diselesaikan bersama mitra terkait. Kemitraan dibangun oleh perguruan tinggi dengan semangat berbagi fasilitas, sumber daya manusia, dana (Cahyana \& Sagala, 2017), perangkat, dan program untuk mencapai tujuan yang sama. Dalam konteks program Relawan TIK, perguruan tinggi dapat bermitra dengan organisasi Relawan TIK.

Ada dua jenis mitra yang diperlukan untuk menjalankan program Relawan TIK, yakni mitra pendukung dari unsur quadruple helix dan mitra penerima manfaat dari unsur nirlaba. Mitra tersebut memberikan data kebutuhan atau permasalahan terkait kesenjangan pengetahuan atau TIK dalam aktivitas pemasukan data dari sistem pendidikan tinggi. Mitra pendukung mengusulkan pengetahuan atau teknologi untuk disampaikan oleh kelompok relawan TIK kepada masyarakat. Selanjutnya masalah

JAS-PT

JURNAL ANALISIS SISTEM PENDIDIKAN TINGGI ISSN $2580-5339$ eISSN $2620-5718$

Volume 2 Nomor 2 Desember 2018 Hal $61-70$

FORUM DOSEN INDONESIA 
tersebut diselesaikan atau kebutuhan tersebut dipenuhi melalui proses produksi pengetahuan dan teknologi menggunakan sumber daya perguruan tinggi dan mitra program (Cahyana \& Sagala, 2017).

Relawan TIK ada di lingkungan perguruan tinggi dalam bentuk unit kerja dosen terkait pengabdian kepada masyarakat, unit kegiatan mahasiswa, atau organisasi komisariat kampus. Bila tercapai kesepakatan kerjasama, maka program kerja tahunan, semesteran, dan / atau mingguan harus dilaksanakan selama kurun waktu kerjasama yang disepakati. Evaluasi di akhir masa periode kerjasama menyoroti pemenuhan butirbutir kesepakatan dan manfaat yang diterima oleh kedua belah pihak.

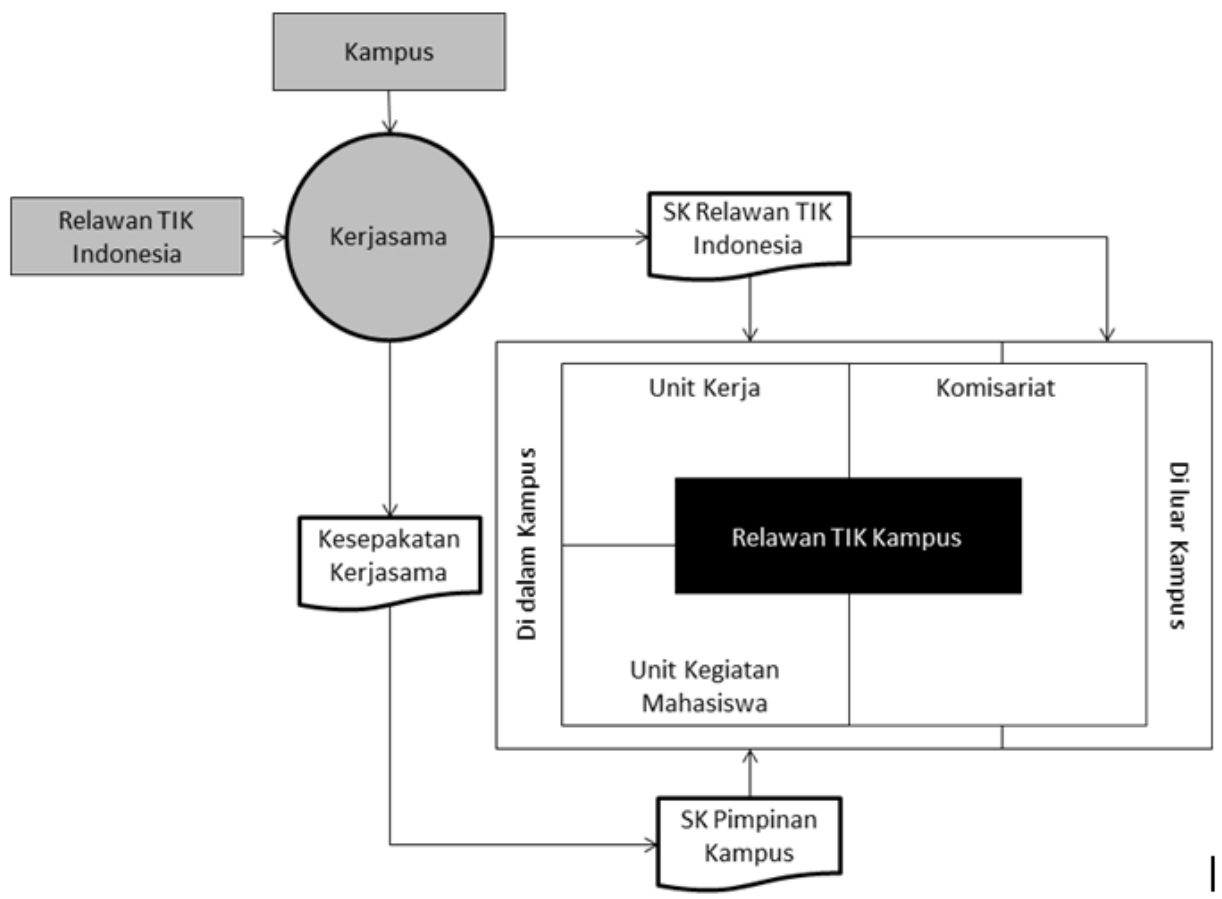

Gambar 4. Skenario Keberadaan Relawan TIK Indonesia dalam Kampus

Butir-butir kesepakatan kerjasama atau manfaat kerjasama harus berkaitan dengan pemenuhan SNPT yang menunjang nilai akreditasi program studi dan perguruan tinggi, seperti:

1. Kepemimpinan publik yang diwujudkan melalui kontribusi dosen atau mahasiswa terhadap masyarakat melalui pelaksanaan tugas jabatan organisasi Relawan TIK di luar kampus;

2. Reputasi mahasiswa karena mendapatkan hibah program kemahasiswaan relawan TIK, dan sebagai relawan TIK pelaksana program kerja terbaik tingkat regional, nasional, atau internasional;

3. Pengembangan kapasitas tenaga pendidik dalam bentuk pendikan dan pelatihan terkait literasi digital, atau peran serta dosen (sebagai peserta atau penyaji) dalam pertemuan ilmiah offline atau online tingkat nasional atau internasional, dengan

JAS-PT

JURNAL ANALISIS SISTEM PENDIDIKAN TINGG

ISSN $2580-5339$

eISSN $2620-5718$

Volume 2

Nomor 2

Desember 2018

Hal $61-70$

FORUM DOSEN INDONESIA topik seputar relawan TIK dan dihadiri oleh dosen atau mahasiswa anggota relawan TIK dari kampus lain;

4. Reputasi dosen karena mendapatkan hibah program pengabdian kepada masyarakat, dan sebagai pengurus atau pembimbing relawan TIK terbaik tingkat regional, nasional, atau internasional;

5. Pengabdian kepada masyarakat berupa program mingguan, semesteran, atau tahunan yang melibatkan organisasi Relawan TIK; 
6. Penelitian terkait relawan TIK yang diseminarkan atau dipublikasikan; dan

7. Kerjasama dengan organisasi Relawan TIK yang memberikan manfaat bagi kampus dan mitra penerima manfaat.

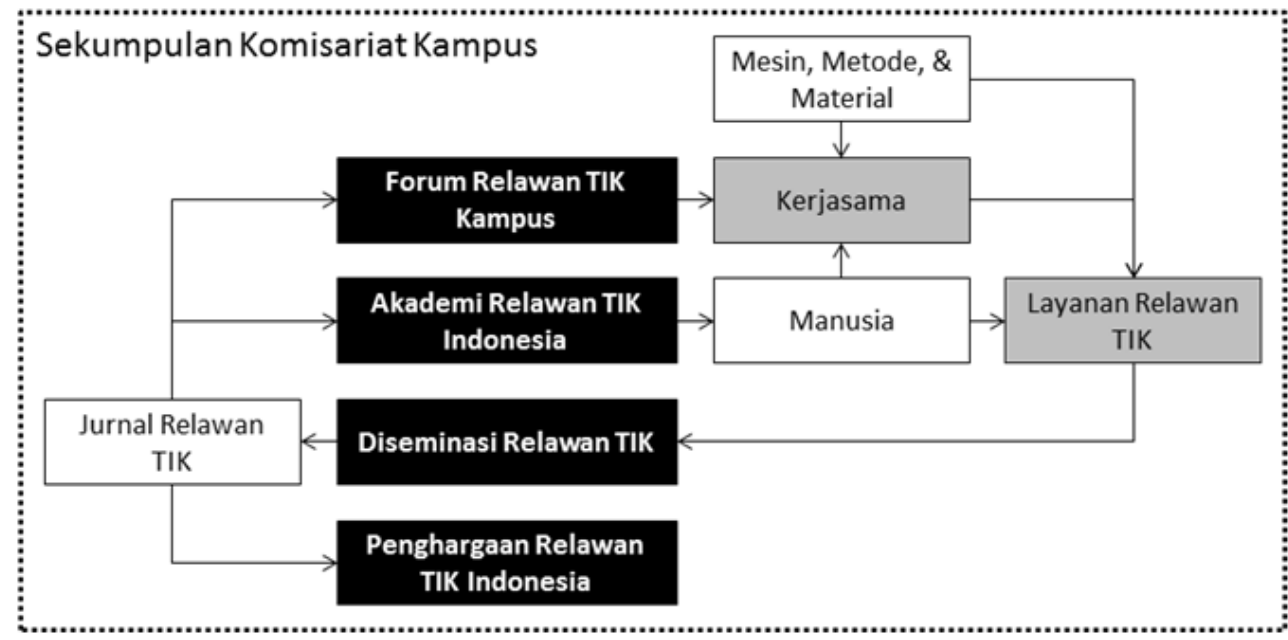

Gambar 5. Kolaborasi Antar Relawan TIK Kampus

Diperlukan divisi atau badan khusus yang bertugas mengelola program yang melibatkan relawan TIK di banyak kampus. Tugas badan ini seperti unit kerja pengelola pengabdian kepada masyarakat sesuai SNP, hanya saja tugas pengelolaannya multi kampus. Setidaknya ada empat elemen penting yang harus ada untuk menjamin keberlangsungan kerjasama organisasi relawan TIK dengan perguruan tinggi:

1. Forum Relawan TIK Kampus yang diselenggarakan secara offline atau online sebagai medium komunikasi dan kerjasama antar kampus dalam melaksanakan layanan relawan TIK;

2. Akademi Relawan TIK Indonesia dalam bentuk sistem pendidikan dan pelatihan offline atau online / elearning untuk membentuk pengetahuan, keterampilan, dan sikap relawan TIK kampus;

3. Diseminasi Relawan TIK dalam Konferensi Relawan TIK Indonesia, Jurnal Relawan TIK, atau Digital Library yang menyajikan hasil pelayanan relawan TIK kampus;

Penghargaan Relawan TIK Kampus baik komisariat kampus atau pelaksana layanan relawan TIK yang berprestasi melalui kegiatan penilaian oleh tim penjamin mutu (yang informasi kinerja komisariat kampusnya tayang dalam situs web atau sistem informasi) atau perlombaan;Dengan mengadopsi model analisis sistem informasi Kelompok Penggerak Masyarakat Informasi (Cahyana, 2015), sistem dan teknologi yang diperlukan untuk menunjang kolaborasi tersebut sebagaimana tampak pada gambar 6 . Platform yang digunakan sebaiknya dapat digunakan atau diakses secara online (melalui jaringan) agar dapat membukakan kesempatan partisipasi relawan dalam kerja kolaboratif antar kampus yang lebih besar lagi. Dengan pemanfaat internet, akses menuju sistem dan perangkat teknologi dapat dilakukan di mana saja dan kapan saja.

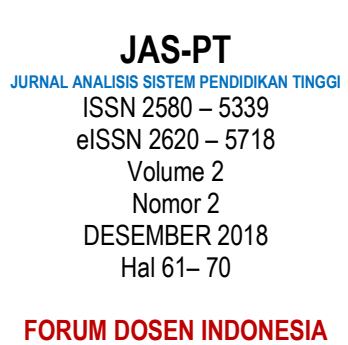

FORUM DOSEN INDONESIA 


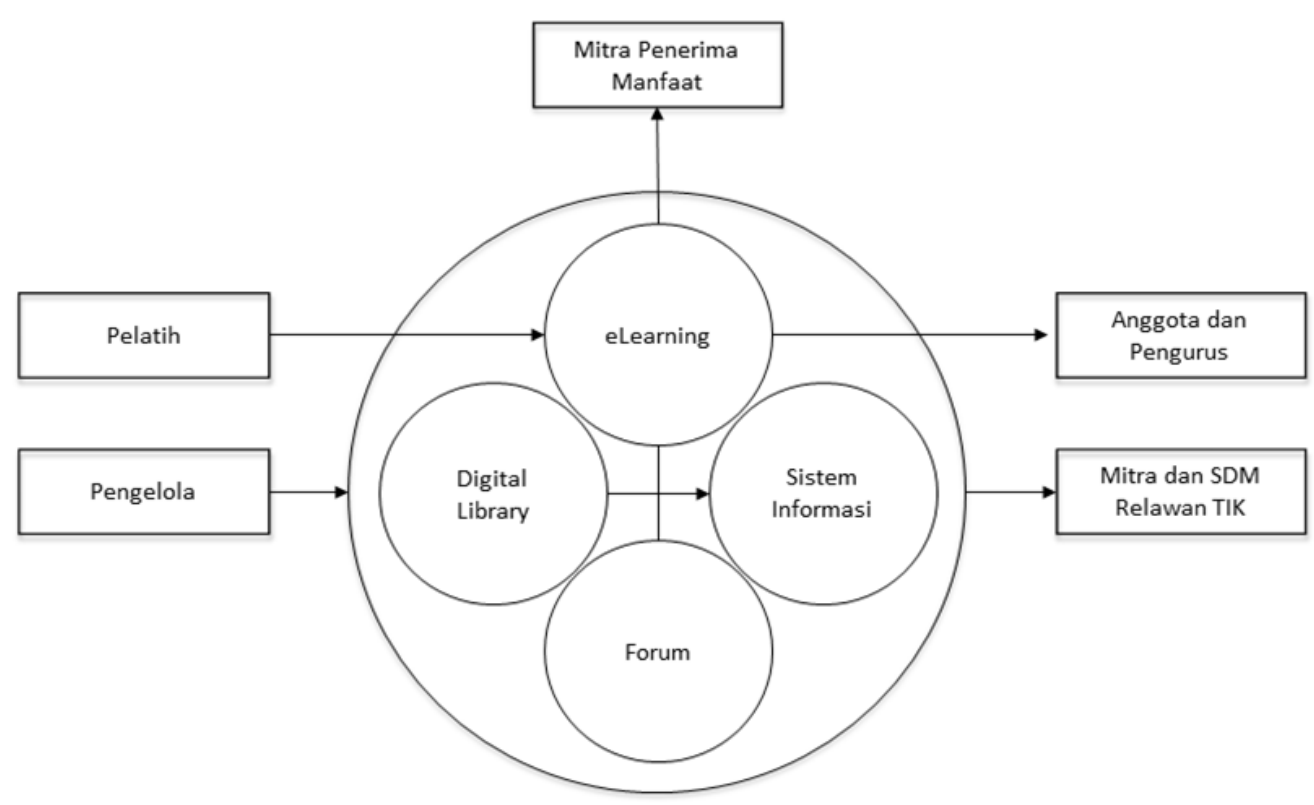

Gambar 6. Sistem dan Teknologi Informasi Relawan TIK

\section{Kesimpulan}

Integrasi Relawan TIK dalam sistem pendidikan tinggi dicapai melalui penerapan aktivitasnya dalam kegiatan intra atau ekstra kurikuler secara terjadwal dalam bentuk program kerja mingguan, semesteran, dan / atau tahunan. Kerjasama dibangun antara kampus dan mitra pendukung agar program kerja dapat dilaksanakan dengan menggunakan sumber daya internal milik kampus dan eksternal kampus milik mitra pendukung. Untuk menjaga keberlanjutan kerjasama, keluaran dari kerjasamanya harus bermanfaat bagi kedua belah pihak, khususnya bagi kampus harus dapat menunjang akreditasi program studi atau institusi. Untuk menjaga agar anggota terus aktif dalam organisasi, perlu dibuat penjenjangan fungsional dan struktural agar pengalaman anggota tidak monoton. Keberlanjutan tersebut penting mengingat tujuan pembangunan masyarakat informasi tidak dapat dicapai dalam waktu sebentar.

\section{Referensi}

Acevedo, M., 2005. Volunteering in the Information Society.

Solidarity@Network_Society.int. [Online]

Available at: $\underline{\text { http://ictlogy.net/bibliography/reports/projects.php?idp=1284 }}$

Alisandi, R. \& Cahyana, R., 2015. Pengembangan Sistem Informasi untuk Perekaman dan Pelaporan Kinerja Kelompok Penggerak Masyarakat Informasi. Jurnal Algoritma.

JAS-PT

JURNAL ANALISIS SISTEM PENDIDIKAN TINGGI

ISSN $2580-5339$

eISSN $2620-5718$

Volume 2

Nomor 2

Desember 2018

Hal $61-70$
Attwood, C., Singh, G., Prime, D. \& Creasey, R., 2003. 2001 Home Office Citizenship Survey : people, families and communities, London: Home Office Research.

Cahyana, R., 2014. The Stages, Three-Layer Infrastructure, and Functional Level Regulation for Development of Information Society within of Information 
Technology Volunteer Actions. International Journal of Basic and Applied Science, 3(1), pp. 28-35.

Cahyana, R., 2015. Model Analisis Sistem Informasi Kelompok Penggerak Masyarakat Informasi. Bandung, Institut Teknologi Bandung.

Cahyana, R., 2016. Memfungsikan Telecenter Sebagai Pusat Pembangunan Ekonomi Digital di Wilayah Perdesaan dengan Melibatkan Relawan Teknologi Informasi. Bogor, Kementrian Komunikasi dan Informatika.

Cahyana, R. \& Sagala, I., 2017. Model Sistem Perubahan dalam Lingkup Program Sarjana. JAS-PT Jurnal Analisis Sistem Pendidikan Tinggi, pp. 1-10.

Gudauskas, R., 2011. National information policy, information infrastructure and libraries. Vilnius, Lithuanian Research Library Consortium.

Karvalics, L. Z., 2007. Information Society - what is it exactly?. Budapest: Midlans State University.

Kemenristekdikti, 2015. Permen Ristekdikti no 44 tahun 2015 tentang Standar Nasional Pendidikan Tinggi, Jakarta: s.n.

Kemkominfo, 2011. Relawan TIK Indonesia : Bersama Membangun Masyarakat Indonesia Informatif. Jakarta: Kementrian Komunikasi dan Informatika.

Linda, L., 2000. Economics of Information Technology and the Media. Singapore: Singapore University Press.

Musick, M. A. \& Wilson, J., 2007. Volunteers: A Social Profile. Bloomington: Indiana University Press.

Rinda Cahyana. Lahir di Ciamis, 17 Oktober 1979. Menyelesaikan pendidikan Sarjana pada program studi Teknik Informatika Sekolah Tinggi Teknologi Garut, Indonesia, pada tahun 2003. Pendidikan jenjang Master pada program studi Informatika Institut Teknologi Bandung, Indonesia, diselesaikan pada tahun 2011.

JAS-PT

JURNAL ANALISIS SISTEM PENDIDIKAN TINGG ISSN $2580-5339$ eISSN $2620-5718$

Volume 2 Nomor 2

DESEMBER 2018 Hal $61-70$

FORUM DOSEN INDONESIA 
JAS-PT

JURNAL ANALISIS SISTEM PENDIDIKAN TINGG

ISSN 2580 - 5339

eISSN 2620 - 5718

Volume 2

Nomor 2

DESEMBER 2018

Hal 61- 70

FORUM DOSEN INDONESIA 